\title{
Immunogenicity evaluation of inactivated virus and purified proteins of porcine circovirus type 2 in mice
}

\author{
Xiaohui Liu ${ }^{\dagger}$, Ting Ouyang ${ }^{\dagger}$, Teng Ma, Hongsheng Ouyang, Daxin Pang and Linzhu Ren ${ }^{*}$ (D
}

\begin{abstract}
Background: Vaccination is considered as an effective and economical way to against PCV2 infection. However, some of commercial available vaccines are based on inactivated viruses, while the others are based on purified protein of PCV2. In the present study, we aimed to compare the immunogenicity of inactivated virus and purified proteins of porcine circovirus type 2 in mice.

Results: The results showed that positive antiserum titers were significantly increased after second, third and fourth immunization using inactivated PCV2 or purified proteins as coating antigen. Moreover, the inactivated PCV2 induced significantly higher levels of PCV2-specific antibodies than that of PCV2 subunit proteins. After PCV2 wild strain challenged, the average daily gain was comparable with that of mice in the mock group, and the sera from both inactivated PCV2-immunized animals and subunit protein Cap+ORF3 + Rep immunized animals had significantly higher neutralizing antibody titers than that of the PBS group. As expected, the neutralizing antibody in the inactivated PCV2 group was significantly higher than that of the subunit protein group. These results indicated that positive antiserum induced by the inactivated PCV2 had a better reactivity and specificity than that of the positive antiserum induced by the purified proteins.
\end{abstract}

Conclusions: The results in the present study demonstrated inactivated PCV2 is more effective than PCV2 subunit proteins in stimulating immune response to against PCV2 infection.

Keywords: Porcine circovirus type 2 (PCV2), Inactivated, Subunit, Immunogenicity, Mice, Vaccine

\section{Background}

Porcine circovirus 2 (PCV2) is the causative agent of porcine circovirus diseases and porcine circovirus-associated diseases (PCVD/PCVAD), including a number of different syndromes and diseases in pigs, such as post-weaning multi-systemic wasting syndrome (PMWS), porcine respiratory disease complex (PRDC), reproductive failure, granulomatous enteritis, necrotizing lymphadenitis, exudative epidermitis and congenital tremor, which are widely present in every major swine farm [1-3].

To date, the exact mechanisms of PCVD/PCVAD are currently unknown. Although several commercial vaccines based on PCV2a are effective in protecting pigs against a challenge with PCV2a, they cannot protect pigs

\footnotetext{
*Correspondence: renlz@jlu.edu.cn

${ }^{\dagger}$ Equal contributors

Jilin Provincial Key Laboratory of Animal Embryo Engineering, College of

Animal Sciences, Jilin University, Changchun, Jilin 130062, China
}

against the PCV2b genotype that is prevalent worldwide or against other PCV2 genotypes $[4,5]$. Therefore, studies focused on an effective vaccine are still urgent and important for PCV2 infection.

Based on current knowledge, many documents were reported either based on inactivated PCV2 or PCV2 subunit proteins [6-9]. However, few studies were reported to compare the efficiency of inactivated PCV2 and PCV2 subunit proteins. Previously, we expressed and purified Rep, ORF3, and different fragments of PCV2 Cap protein $[6,7]$. In the present study, we aimed to compare the immunogenicity of inactivated virus and purified proteins of PCV2 in mice. The results of the present study may be useful for production of PCV2 vaccine.

(C) The Author(s). 2018 Open Access This article is distributed under the terms of the Creative Commons Attribution 4.0 International License (http://creativecommons.org/licenses/by/4.0/), which permits unrestricted use, distribution, and reproduction in any medium, provided you give appropriate credit to the original author(s) and the source, provide a link to the Creative Commons license, and indicate if changes were made. The Creative Commons Public Domain Dedication waiver (http://creativecommons.org/publicdomain/zero/1.0/) applies to the data made available in this article, unless otherwise stated. 


\section{Methods}

\section{Ethics statement}

All animal experiments were prospectively planned and all procedures were carried out under an ethical approval granted by the Animal Care and Ethics Committee of Jilin University (Changchun, China). The Animal Ethics Committee approval number was LSXK2018051.

\section{Viruses and proteins}

The titer of PCV2 strain CC1 [10] on PK-15 cell was $10^{9}$ $\mathrm{TCID}_{50} / \mathrm{mL}$. PCV2 strain CC1 was inactivated by $0.4 \%$ of formaldehyde $(v / v)$ for $72 \mathrm{~h}$ at $37{ }^{\circ} \mathrm{C}$.

PCV2 Cap, Rep and ORF3 proteins were prepared and purified according to the protocols described previously $[6,7]$. Briefly, the $\Delta$ Cap17-233 with truncated version of the Cap gene lacking the $5^{\prime}$-end 48 nt encoding the $\mathrm{N}$ terminal 16 amino acid residues was amplified and subcloned into the expression vector pET28b (+) (Novagene, Germany) to generate recombinant expression plasmids pET28b- $\triangle$ Cap17-233. The ORF3 and Rep genes were amplified and subcloned into the expression vector pET28c (+) (Novagene, Germany) to generate recombinant expression plasmids, pET-28c-ORF3 and pET-28c-Rep, respectively. The plasmids were transformed into $E$. coli BL21 (DE3) competent cells and expressed with IPTG $(1.0 \mathrm{mmol} / \mathrm{L})$ induction. Proteins were purified using HisPur $^{\text {TM }}$ Ni-NTA Resin (Thermo scientific) according to the manufacturer's instruction and stored at $4{ }^{\circ} \mathrm{C}$ for use within one week or at $-80{ }^{\circ} \mathrm{C}$ for use after a longer time.

\section{Animal immunization}

Specific pathogen-free (SPF) BALB/c mice were purchased from the Laboratory Animal Center, Norman Bethune Health Science Center of Jilin University (Changchun, China). Mice were acclimatized at an environment with a temperature of 24-26 and humidity of $60 \%$ for 7 days before experiment.

To compare the immunogenicity of inactivated virus and purified proteins, thirty female BABL/C mice, 5 weeks old, were randomly divided into six groups (5 mice per group), including inactivated virus immunized group (7 $\log 10$ $\left.\mathrm{TCID}_{50} / \mathrm{mL}, \mathrm{A}\right)$, Cap+ORF3 immunized group $(\mathrm{mol} / \mathrm{mol}=$ $1: 1$, B), Cap+Rep immunized group $(\mathrm{mol} / \mathrm{mol}=1: 1, C)$, ORF3 + Rep immunized group $(\mathrm{mol} / \mathrm{mol}=1: 1, \quad \mathrm{D})$, Cap +ORF3 + Rep immunized group ( $\mathrm{mol} / \mathrm{mol}=1: 1: 1, \mathrm{E})$, and PBS group (control group), and housed in separate isolation rooms. Preimmune serum was collected prior to immunization. The inactivated virus $(100 \mu \mathrm{L})$ or purified proteins $(100 \mu \mathrm{g})$ were emulsified as a 1:1 $(\mathrm{v} / \mathrm{v})$ mixture with a complete Freund's adjuvant (Sigma). Mice were immunized subcutaneously with $200 \mu \mathrm{L}$ of the purified proteins or the inactivated virus. Then, the mice were injected subcutaneously with $200 \mu \mathrm{L}$ of the proteins or the inactivated virus mixed with incomplete Freund's adjuvant (Sigma) two week, four weeks and six weeks later, respectively. One week after the fourth immunization, the mice were euthanized by cervical dislocation and the sera were harvested for antibody analyses. The sera were collected and stored in aliquots at $-20^{\circ} \mathrm{C}$.

To further demonstrate whether the inactivated virus and purified proteins induce a sufficiently protective immune response against PCV2, thirty female BABL/C mice, 5 weeks old, were randomly divided into three groups (10 mice per group), including inactivated virus immunized group ( $\left.9 \log 10 \mathrm{TCID}_{50} / \mathrm{mL}, \mathrm{A}\right)$, Cap+ORF3 + Rep immunized group $(\mathrm{mol} / \mathrm{mol}=1: 1: 1, \mathrm{~B})$, and negative control group (PBS), and housed in separate isolation rooms. Preimmune serum was collected prior to immunization. The inactivated virus $(100 \mu \mathrm{L})$ or purified proteins $(100 \mu \mathrm{g}$, Cap:Rep:ORF3 = 34:43:23) were emulsified as a 1:1 ( $\mathrm{v} / \mathrm{v})$ mixture with a complete Freund's adjuvant (Sigma). Mice were immunized subcutaneously with $200 \mu \mathrm{L}$ of the purified proteins or inactivated virus. Then, the mice were injected subcutaneously with $200 \mu \mathrm{L}$ of the proteins or the inactivated virus mixed with incomplete Freund's adjuvant (Sigma) two week, four weeks and six weeks later, respectively. $72 \mathrm{~h}$ after each immunization, the sera of five mice per group were harvested. Two weeks following fourth immunization, all the mice were infected with $200 \mu \mathrm{L}$ of PCV2 at 7 $\log 10 \mathrm{TCID}_{50} / \mathrm{mL}$ or $200 \mu \mathrm{L}$ of PBS by intramuscular injection, respectively. All mice were observed three times daily for changes in physical appearance and deaths (if any) for up to 14 days post virus exposure. Generally, mice were weighed every other day to determine the average weight change of the group and were observed for clinical signs of distress. Fourteen days post infection, mice were euthanized by cervical dislocation and the sera were collected and stored in aliquots at $-20{ }^{\circ} \mathrm{C}$.

\section{Assay of mice blood antibody levels}

Antibody levels in mice blood was measured by ELISA. Briefly, ELISA plates (Costar) were coated with $100 \mu \mathrm{L}$ of PCV2 or purified protein, which was diluted to a final concentration of $2 \mu \mathrm{g} / \mathrm{mL}$ in coating buffer $(\mathrm{PH}=9.6)$, at $4{ }^{\circ} \mathrm{C}$ overnight and then washed with PBS containing 0 . 05\% Tween 20 (PBST, PH = 7.4) for three times. Unspecific binding of the antibodies was avoided by blocking with $100 \mu \mathrm{L}$ of $0.5 \%$ BSA for $30 \mathrm{~min}$ at room temperature. After washing three times with PBST, $100 \mu \mathrm{L}$ of appropriately diluted serum in PBST containing $0.5 \%$ BSA was added and incubated for $30 \mathrm{~min}$ at $37{ }^{\circ} \mathrm{C}$. After washing three times with PBST, the bound antibodies were incubated with $100 \mu \mathrm{L}$ of goat antimouse IgG (1:1000). After incubation for $1 \mathrm{~h}$ at room temperature and three PBST washes, $100 \mu \mathrm{L}$ of TMB 
(Sigma) was added to each well and the mixture was incubated for $15 \mathrm{~min}$ at room temperature. The reaction was stopped by adding $100 \mu \mathrm{L}$ of $1 \mathrm{~N}$ sulfuric acid to the mixture, and the optical density at $450 \mathrm{~nm}$ was measured (Bio-RAD microplate reader).

\section{Virus neutralization test (VNT)}

Neutralization assay was performed to assess the ability of the serum samples to neutralize the PCV2 according to the protocol described by Jin [11]. Briefly, serum samples were heat inactivated at $56^{\circ} \mathrm{C}$ for $30 \mathrm{~min}$, followed by serial dilution in 2-fold increments in Dulbecco's modified Eagle medium (DMEM) supplemented with 2\% of fetal bovine serum (FBS), and mixed 1:1 with 200 $\mathrm{TCID}_{50}$ of PCV2 strain CC1 for $2 \mathrm{~h}$ at $37^{\circ} \mathrm{C}$. Thereafter, $100 \mu \mathrm{L}$ of serum-virus mixture was added to $50 \%$ confluency of PK-15 cells and incubated for $1 \mathrm{~h}$ at $37^{\circ} \mathrm{C}$. After incubation, the serum-virus mixture was removed, and the cells were washed with PBS for three times and further incubated in DMEM supplemented with $2 \%$ of FBS at $37^{\circ} \mathrm{C}$ and $5 \% \mathrm{CO}_{2}$. After incubation for $72 \mathrm{~h}$, an indirect fluorescence assay (IFA) was performed as previously described by Yang [12].

\section{Statistical analysis}

Statistical significance was calculated using one-way or two-way analysis of variance (ANOVA), followed by the Bonferroni multiple comparison test. Statistical analysis was performed using GraphPad Prism software, version 5 (GraphPad Software, SanDiego, CA). The results were statistically significant at $p<0.05$. For each separate set of assays, at least 3 independent experiments were evaluated. The results are expressed as the mean \pm standard deviation (SD).

\section{Results}

Inactivated PCV2 is more effective than four PCV2 subunit proteins in stimulating immune response

To compare immunogenicity, inactivated PCV2 and four different combinations of PCV subunit proteins (different combinations of Cap+ORF3, Cap+Rep, ORF3 + Rep, and Cap+ORF3 + Rep) were used as antigens to raise antiserum, respectively. After four immunizations, the antisera were collected and detected by ELISA using PCV2 as coating antigen. The results showed that the inactivated PCV2 induced significantly higher levels of PCV2-specific antibodies than that of the PCV2 subunit proteins, indicating the inactivated PCV2 was more effective than the PCV2 subunit proteins in stimulating immune response (Table 1). Furthermore, PCV2 subunit protein Cap+ORF3 + Rep showed a better immunogenicity than the other subunit proteins, whereas antibodies were undetectable in the mock groups. Therefore, the inactivated PCV2 and the subunit protein $\mathrm{Cap}+\mathrm{ORF} 3+$ Rep were selected in the following studies.

To compare serum antibody level after immunization in mice, $200 \mathrm{uL}$ of sera were obtained from 5 mice of each group by needle puncture of tail tip vein $72 \mathrm{~h}$ after each immunization, followed by ELISA. The results of ELISA showed that positive antiserum titers were significantly increased after second, third and fourth immunization using inactivated PCV2 (Fig. 1) or purified proteins (Fig. 2) as coating antigen. Furthermore, the antiserum developed from the inactivated PCV2 was significantly higher than that of the purified proteins group when inactivated PCV2 was used as coating antigen (Fig. 1). Moreover, when purified proteins Cap + Rep (1:1) was used as coating antigen, the antisera developed from both inactivated PCV2 and purified proteins were significantly higher than that of the control (PBS) group (Fig. 2). These results indicated that positive antiserum induced by the inactivated PCV2 had a better reactivity and specificity than that of the purified proteins.

\section{Inactivated PCV2 induced more effective immunity than purified subunit proteins against PCV2}

To elucidate whether the inactivated PCV2 and purified protein were effective in protecting mice against PCV2, the mice were infected with $200 \mu \mathrm{L}$ of PCV2 at $7 \log 10 \quad \mathrm{TCID}_{50} / \mathrm{mL}$ by intramuscular injection 14 days after the fourth immunization. The results showed that average daily gain had no significant difference between the groups as well as in each group,

Table 1 ELISA results (Mean \pm SD) of different groups in stimulating immune response

\begin{tabular}{llllllll}
\hline Dilution of Antiserum & Inactivated virus & Cap+ORF3 & Cap+Rep & ORF3 + Rep & Cap+ORF3 + Rep & Negative Serum & PBS \\
\hline $1 / 200$ & $1.1430 \pm 0.0463$ & $0.1437 \pm 0.0161$ & $0.1033 \pm 0.0062$ & $0.0633 \pm 0.0045$ & $0.2972 \pm 0.0683$ & $0.0649 \pm 0.0047$ & $0.0516 \pm 0.0004$ \\
$1 / 400$ & $1.1476 \pm 0.0423$ & $0.1985 \pm 0.0557$ & $0.0802 \pm 0.0101$ & $0.0554 \pm 0.0021$ & $0.1666 \pm 0.0431$ & $0.0509 \pm 0.0046$ & $0.0558 \pm 0.0016$ \\
$1 / 800$ & $1.1624 \pm 0.0955$ & $0.1712 \pm 0.0440$ & $0.0628 \pm 0.0037$ & $0.0565 \pm 0.0017$ & $0.1132 \pm 0.0225$ & $0.0514 \pm 0.0012$ & $0.0556 \pm 0.0011$ \\
$1 / 1600$ & $1.1033 \pm 0.0981$ & $0.1146 \pm 0.0231$ & $0.0649 \pm 0.0054$ & $0.0565 \pm 0.0023$ & $0.0550 \pm 0.0012$ & $0.0504 \pm 0.0016$ & $0.0575 \pm 0.0023$ \\
$1 / 3200$ & $1.0049 \pm 0.1002$ & $0.0802 \pm 0.0104$ & $0.0561 \pm 0.0016$ & $0.0511 \pm 0.0010$ & $0.0512 \pm 0.0016$ & $0.0517 \pm 0.0009$ & $0.0558 \pm 0.0015$ \\
$1 / 6400$ & $0.8501 \pm 0.0854$ & $0.0634 \pm 0.0042$ & $0.0536 \pm 0.0011$ & $0.0524 \pm 0.0007$ & $0.0541 \pm 0.0012$ & $0.0532 \pm 0.0014$ & $0.0536 \pm 0.0011$ \\
$1 / 12800$ & $0.7245 \pm 0.0916$ & $0.0567 \pm 0.0017$ & $0.0531 \pm 0.0007$ & $0.0543 \pm 0.0005$ & $0.0557 \pm 0.0003$ & $0.0526 \pm 0.0006$ & $0.0562 \pm 0.0012$
\end{tabular}

Note:Detection limits were underlined. ${ }^{*}$ Positive, Sample/negative serum $\geq 2$ 

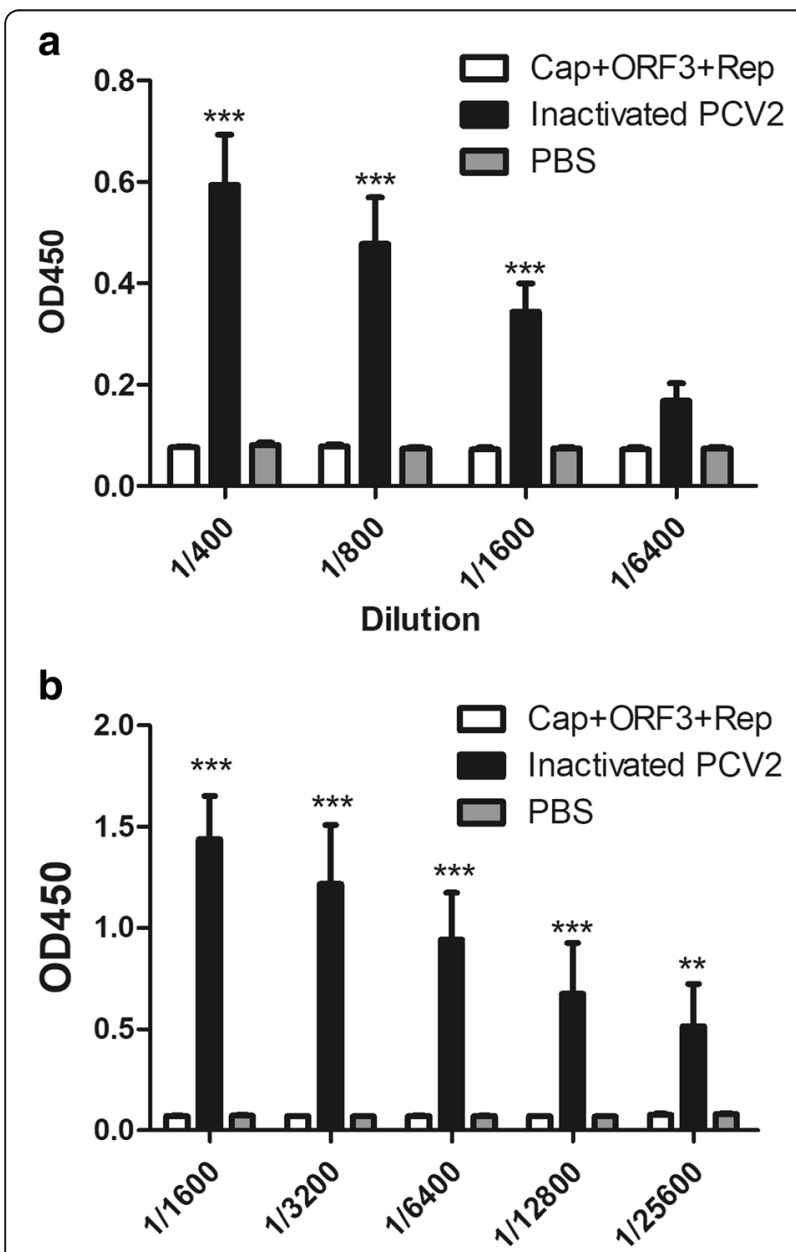

Dilution

C

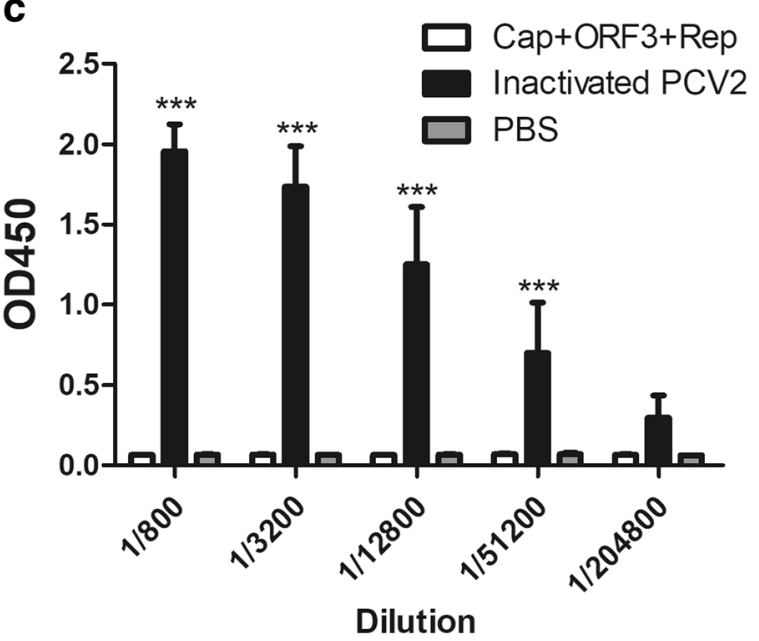

Fig. 1 Serum antibody level after different immunizations in mice. Inactivated PCV2 and subunit protein Cap+ORF3 + Rep were used as antigens to raise antiserum, respectively. After each immunization, the antisera were collected as described in the Materials and methods section. ELISA was performed using PCV2 as coating antigen. (a) Second immune; (b) Third immune; (c) Fourth immune

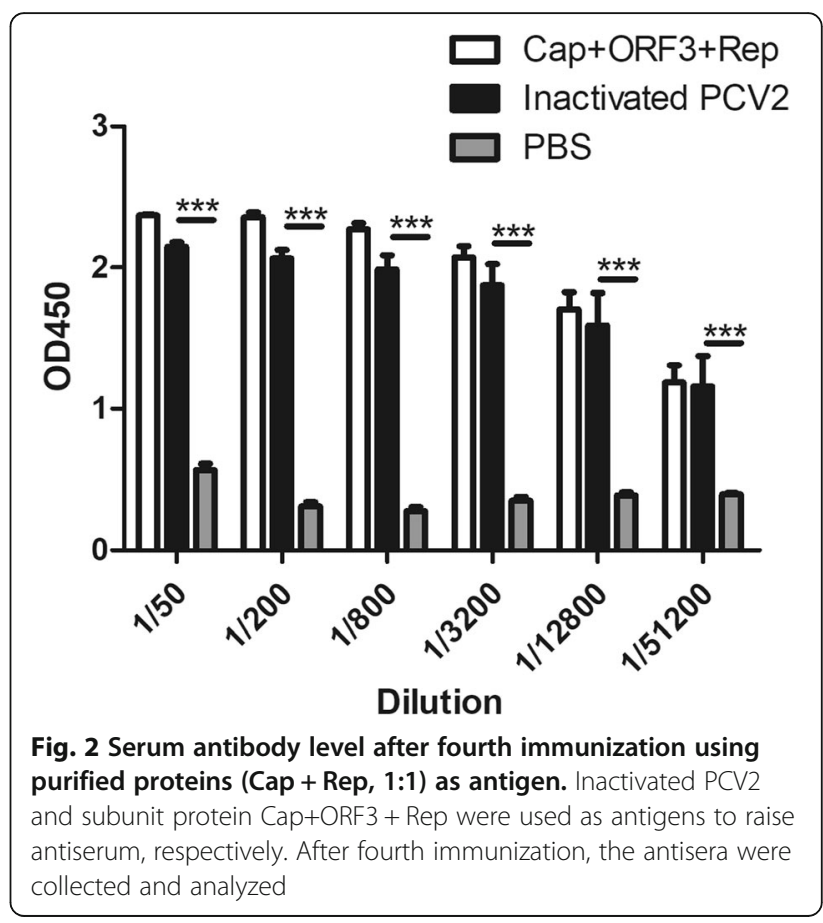

and the weight gain was not altered by immunization in mice (Fig. 3).

The antisera from each group were collected and detected by ELISA using inactivated PCV2, Cap protein and Rep protein as coating antigen, respectively. The results demonstrated that serum antibody developed from the inactivated PCV2 showed high levels using inactivated PCV2, Cap protein or Rep protein

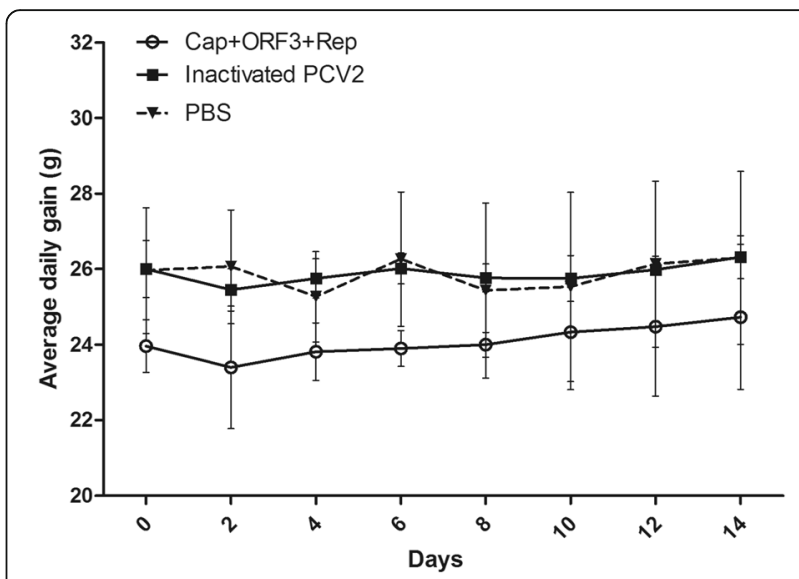

Fig. 3 Average daily gain. Thirty female BABL/C mice, 5 weeks old, were randomly divided into three groups and immunized subcutaneously with $200 \mu \mathrm{L}$ of the purified proteins or inactivated virus. Two weeks following fourth immunization, all the mice were infected with $200 \mu \mathrm{L}$ of PCV2 at $7 \log 10 \mathrm{TCID} 50 / \mathrm{mL}$ or $100 \mu \mathrm{L}$ of PBS by intramuscular injection, respectively. All mice were observed three times daily for changes in physical appearance and deaths (if any) for up to 14 days post virus exposure. Generally, mice were weighed every other day to determine the average weight gain of the group 
as coating antigen, respectively (Fig. 4). Furthermore, serum antibody developed from the subunit protein Cap+ORF3 + Rep showed high levels using Cap protein or Rep protein as coating antigen (Figs. $4 \mathrm{~b}$ and c).

To assess the ability of the serum samples to neutralize the PCV2, neutralization assay was performed and evaluated using IFA. The results showed that the sera from both inactivated PCV2-immunized animals and subunit protein Cap+ORF3 + Rep immunized animals had significantly higher neutralizing antibody titers than that of PBS group (Fig. 5). These results indicated that the inactivated PCV2 and subunit protein Cap +ORF3 + Rep were effective in inducing PCV2neutralizing antibody responses in mice. Moreover, the neutralizing antibody in the inactivated PCV2 group was significantly higher than that of the subunit protein group. Therefore, these results indicated that immune effect of the inactivated PCV2 was better than the PCV2 subunit protein Cap+ORF3 + Rep in the present study.

\section{Discussions}

The PCV2 genome has eleven open reading frames (ORFs), ORF1 to ORF11 [3]. ORF1 of PCV2 is highly conserved and encodes viral DNA replication-associated proteins, and ORF2 encodes the relatively variable structural protein Cap. Currently, both Rep and Cap are considered as significant immunogenic proteins of PCV2 that play important roles in cell-mediated immunity to constrain PCV2 replication and prevent the progression of PCV2 infection toward PCVD/PCVAD [13-15]. It was reported that PCV2-inoculation induced a cellular immunity against Cap protein as well as Rep protein in pigs $[14,15]$. There are eight replication-associated proteins encoded by ORF1 gene, including two major products (designated Rep and Rep0) and six minor products (designated Rep3a, Rep3b, Rep3c, NS515, NS672, and NS0) [13]. Rep proteins likely contribute to viral pathogenicity in vivo [16]. It was reported that the Rep can not only interact with cellular filament protein and transcriptional regulator c-myc, but also can interact with Cap protein [17], indicating Rep proteins are important in PCV2 infection and pathogenicity. Additionally, Rep protein, especially N-terminus of Rep (RepN), is conserved and immunogenic [18]. However, the Nglycosylation 23-25 aa, 256-258 aa mutation of Rep protein reduced virus replication, but 286-288 aa mutation can enhance virus replication in PK-15 cells [19]. Previously, we found that the reactivity of the antiserum of Rep protein in PCV2 infected cells was significantly better than that of ORF3 [7]. The possible reason was that different native forms encoded by the viral ORF1 gene in the PCV2-infected cells might enhance the binding affinity of the polyclonal antibody and the

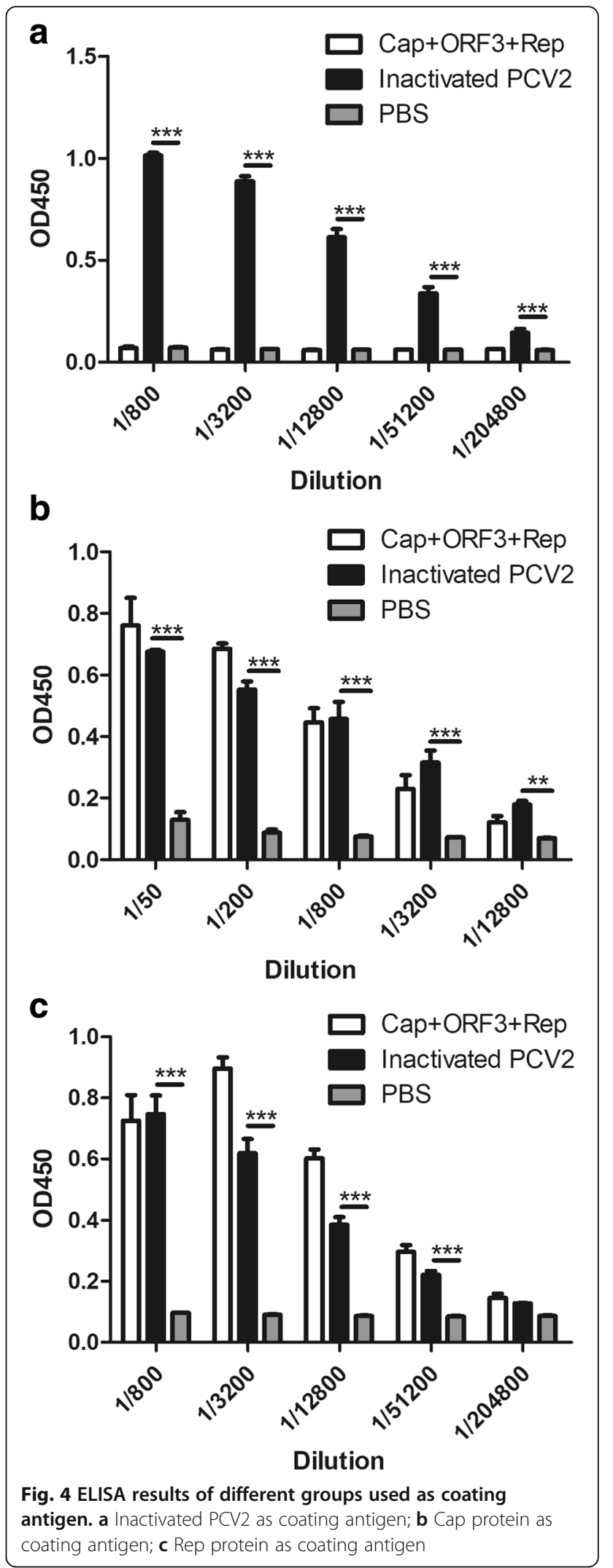




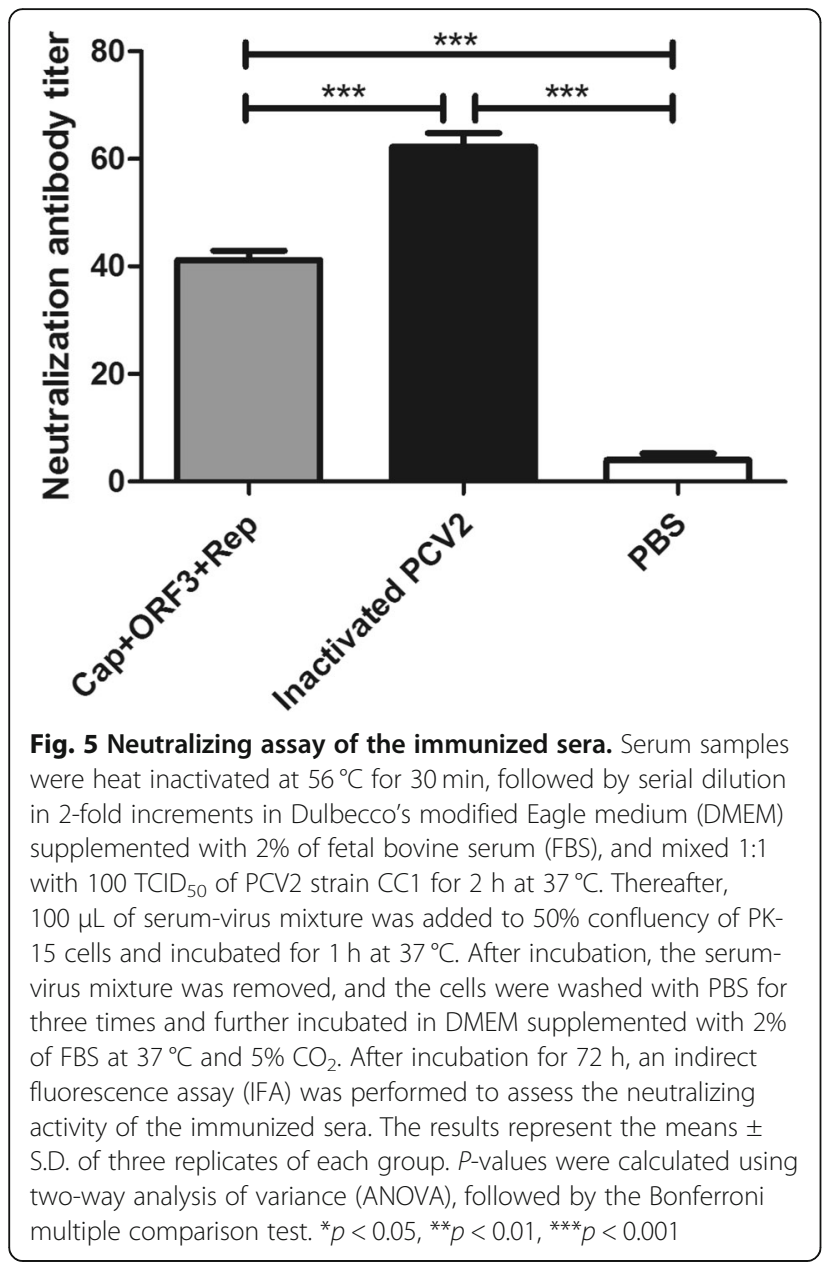

replication-associated proteins [7]. These results indicate that the Rep protein is promising for PCV2 antibody and vaccine development [7]. Moreover, many reports showed that ORF3 protein $(11.9 \mathrm{kDa})$ not only involved in PCV2-induced apoptosis by activating caspase- 8 and caspase- 3 pathways, but also played an important role in viral pathogenesis [3, 20-23]. T lymphocyte responses to PCV2 are primarily directed toward epitopes of Rep and ORF3 proteins [24]. Therefore, we propose that different combinations of PCV2 proteins can induce immunogenicity. In this study, we compared immunogenicity of four different combinations of PCV2 proteins (Cap+ORF3, $\mathrm{Cap}+\mathrm{Rep}, \mathrm{ORF} 3+\mathrm{Rep}$, and Cap+ORF3 + Rep). The results demonstrated that the subunit protein Cap+ORF3 + Rep showed a better immunogenicity than the other PCV2 subunit proteins. Therefore, subunit protein Cap $+\mathrm{ORF} 3+$ Rep were selected in the following studies to compare with inactivated PCV2.

Vaccination is considered as an effective and economical way to against PCV2 infection. Some of commercial available vaccines are based on inactive viruses, while the others are based on purified protein of PCV2. Although subunit vaccines are safe, however, their immunogenicity is low [25]. Therefore, it is difficult to choose an economical vaccine. To elucidate whether the inactivated PCV2 and purified protein were effective in protecting mice against PCV2, the mice were infected with PCV2 by intramuscular injection 14 days after the fourth immunization. As expected, the average daily gain was comparable with that of mice in the mock group, and the inactivated PCV2 and the purified protein Cap +ORF3 + Rep can significantly induced PCV2neutralizing antibody in serum. However, serum antibody developed from the inactivated PCV2 showed higher levels using inactivated PCV2, Cap protein or Rep protein as coating antigen, respectively. Furthermore, the neutralizing antibody in the inactivated PCV2 group was significantly higher than that of the subunit protein group. These results demonstrated that the inactivated virus can induce superior immune responses than that of subunit viral proteins, which were consistent with the results reported by the other groups [26]. The results of the present study indicated that inactivated PCV2 is more effective than purified proteins against PCV2.

Adjuvant is crucial for efficacy of vaccines. In this study, the most commonly used adjuvant, Freund's adjuvant, was used. The results showed that high levels of specific antibodies were induced in mice, indicating both antigens and adjuvant were effective. There are different classes of adjuvants that can push immune response in different directions, including inorganic compounds, mineral oil, bacterial products, and cytokines, etc. [27, 28]. However, each adjuvant has its advantages and disadvantages. It was reported that GM-CSF as an adjuvant with PCV2 subunit vaccines markedly increases specific humoral immune response [25]. Previously, we found that immunological reactions were significantly increased in HMGCRinhibited cells and mice [29, 30], and IL-2 can enhance PCV2 infection in vitro and in vivo [12, 31]. Thus, we hypothesis that IL-2 used as an adjuvant, combined with downregulated HMGCR, can induce stronger immune response in vivo. Further studies are in progress to test this hypothesis.

\section{Conclusions}

In conclusion, the positive antiserum of inactivated PCV2 had a better reactivity and specificity compared with that of the purified proteins. The inactivated PCV2 can induce better immune response to protect mice against PCV2 infection than that of the PCV2 subunit proteins used in this study. The results in the present study may be useful for production of PCV2 vaccine. 


\section{Abbreviations}

ORF: Open reading frame; PCV2: Porcine circovirus 2; PCVD/PCVAD: Porcine circovirus diseases and porcine circovirus-associated diseases; PMWS: Postweaning multi-systemic wasting syndrome; PPV: Porcine parvovirus; PRDC: Porcine respiratory disease complex; PRRSV: Porcine reproductive and respiratory syndrome virus; SIV: Swine influenza virus; SPF: Specific pathogenfree; TCID: Tissue culture infective dose.

\section{Funding}

This work was financially supported by the National Key Research and Development Program of China (No. 2017YFD0500103), the National Natural Science Foundation of China (No. 31772747 and 31272385), the Program for JLU Science and Technology Innovative Research Team (JLUSTIRT, No. 2017TD-28), the Fundamental Research Funds for the Central Universities, the Graduate Innovation Fund of Jilin University, the Program for Changjiang Scholars and the University Innovative Research Team (No. IRT1248).

\section{Availability of data and materials}

The datasets used and/or analyzed during the current study are available from the corresponding author on reasonable request.

\section{Authors' contributions}

LXH, OYT and MT performed the laboratory tests and drafted the manuscript. OYHS, PDX and RLZ conceived the study and participated in its design. RLZ and OYHS participated in the data analysis and results interpretation. All authors critically read and contributed to the manuscript, approving its final version.

\section{Ethics approval and consent to participate}

All animal experiments were approved by the Animal Care and Ethics Committee of Jilin University (Changchun, China)

\section{Competing interests}

The authors declare that they have no competing interests.

\section{Publisher's Note}

Springer Nature remains neutral with regard to jurisdictional claims in published maps and institutional affiliations.

Received: 16 January 2018 Accepted: 16 April 2018

Published online: 23 April 2018

\section{References}

1. Segales J. Porcine circovirus type 2 (PCV2) infections: clinical signs, pathology and laboratory diagnosis. Virus Res. 2012;164(1-2):10-9.

2. Finsterbusch T, Mankertz A. Porcine circoviruses-small but powerful. Virus Res. 2009;143(2):177-83.

3. Ren L, Chen X, Ouyang H. Interactions of porcine circovirus 2 with its hosts. Virus Genes. 2016:52(4):437-44.

4. Meng XJ. Porcine circovirus type 2 (PCV2): pathogenesis and interaction with the immune system. Annu Rev Anim Biosci. 2013;1:43-64.

5. Afghah Z, Webb B, Meng XJ, Ramamoorthy S. Ten years of PCV2 vaccines and vaccination: is eradication a possibility? Vet Microbiol. 2017;206:21-8.

6. Chen F, Yang X, Pang D, Peng Z, Dong M, Liu X, Ouyang H, Ren L. Expression, purification and antibody preparation using different constructs of PCV2 capsid protein. Int J Biol Macromol. 2014;67:289-94.

7. Peng Z, Ma T, Pang D, Su D, Chen F, Chen X, Guo N, Ouyang T, Ouyang H, Ren L. Expression, purification and antibody preparation of PCV2 rep and ORF3 proteins. Int J Biol Macromol. 2016;86:277-81.

8. Li D, Du Q, Wu B, Li J, Chang L, Zhao X, Huang Y, Tong D. Immunogenicity of adenovirus vaccines expressing the PCV2 capsid protein in pigs. Vaccine. 2017;35(36):4722-9.

9. Zhang G, Jia P, Cheng G, Jiao S, Ren L, Ji S, Hu T, Liu H, Du Y. Enhanced immune response to inactivated porcine circovirus type 2 (PCV2) vaccine by conjugation of chitosan oligosaccharides. Carbohydr Polym. 2017:166:64-72.

10. Yang X, Chen F, Cao Y, Pang D, Ouyang H, Ren L. Complete genome sequence of porcine circovirus 2b strain CC1 J Virol. 2012;86(17):9536.

11. Jin J, Park C, Cho SH, Chung J. The level of decoy epitope in PCV2 vaccine affects the neutralizing activity of sera in the immunized animals. Biochem Bioph Res Co. 2018;496(3):846-51.
12. Yang $X$, Chen F, Cao Y, Pang D, Ouyang H, Ren L. Comparative analysis of different methods to enhance porcine circovirus 2 replication. J Virol Methods. 2013;187(2):368-71.

13. LV QZ, Guo KK, Zhang YM. Current understanding of genomic DNA of porcine circovirus type 2. Virus Genes. 2014;49(1):1-10.

14. Fort M, Sibila M, Nofrarias M, Perez-Martin E, Olvera A, Mateu E, Segales J. Porcine circovirus type 2 (PCV2) cap and rep proteins are involved in the development of cell-mediated immunity upon PCV2 infection. Vet Immunol Immunopathol. 2010;137(3-4):226-34.

15. Fort M, Sibila M, Nofrarias M, Perez-Martin E, Olvera A, Mateu E, Segales J. Evaluation of cell-mediated immune responses against porcine circovirus type 2 (PCV2) cap and rep proteins after vaccination with a commercial PCV2 sub-unit vaccine. Vet Immunol Immunopathol. 2012;150(1-2):128-32.

16. Hua T, Wang $X$, Bai J, Zhang L, Liu J, Jiang P. Attenuation of porcine circovirus type- $2 \mathrm{~b}$ by replacement with the rep gene of porcine circovirus type-1. Virus Res. 2013;173(2):270-9.

17. Timmusk S, Fossum C, Berg M. Porcine circovirus type 2 replicase binds the capsid protein and an intermediate filament-like protein. J Gen Virol. 2006; 87(Pt 11):3215-23.

18. Meng T, Jia Q, Liu S, Karuppannan AK, Chang CC, Kwang J. Characterization and epitope mapping of monoclonal antibodies recognizing $\mathrm{N}$-terminus of rep of porcine circovirus type 2. J Virol Methods. 2010;165(2):222-9.

19. Shi J, Peng Z, Fu F, Xu S, Xu S, Cong X, Yuan X, Yu J, Wu J, Sun W, et al. Mutant rep protein of the porcine circovirus type $2 \mathrm{~N}$-glycosylation:23-25aa, 256-258aa mutation reduced virus replication but 286-288aa mutation enhanced virus replication in PK-15 cells. Vet Microbiol. 2015;177(3-4):370-2.

20. Liu J, Chen I, Kwang J. Characterization of a previously unidentified viral protein in porcine circovirus type 2-infected cells and its role in virusinduced apoptosis. J Virol. 2005;79(13):8262-74.

21. Liu J, Chen I, Du Q, Chua H, Kwang J. The ORF3 protein of porcine circovirus type 2 is involved in viral pathogenesis in vivo. J Virol. 2006;80(10): 5065-73.

22. He JL, Dai D, Zhou N, Zhou JY. Analysis of putative ORF3 gene within porcine circovirus type 2. Hybridoma (Larchmt). 2012;31(3):180-7.

23. Choi CY, Rho SB, Kim HS, Han J, Bae J, Lee SJ, Jung WW, Chun T.The ORF3 protein of porcine circovirus type 2 promotes secretion of IL- 6 and IL-8 in porcine epithelial cells by facilitating proteasomal degradation of regulator of $\mathrm{G}$ protein signalling 16 through physical interaction.J Gen Virol.2015;96(Pt 5):1098-108

24. Stevenson LS, Gilpin DF, Douglas A, McNeilly F, McNair I, Adair BM, Allan GM. T lymphocyte epitope mapping of porcine circovirus type 2. Viral Immunol. 2007:20(3):389-98.

25. Zhang $H$, Qian P, Peng B, Shi L, Chen H, Li X. A novel subunit vaccine coexpressing GM-CSF and PCV2b cap protein enhances protective immunity against porcine circovirus type 2 in piglets. Vaccine. 2015;33(21):2449-56.

26. Stoel M, Pool J, de Vries-Idema J, Zaaraoui-Boutahar F, Bijl M, Andeweg AC, Wilschut J, Huckriede A. Innate responses induced by whole inactivated virus or subunit influenza vaccines in cultured dendritic cells correlate with immune responses in vivo. PLoS One. 2015;10(5):e0125228.

27. Johnson AG. Molecular adjuvants and immunomodulators: new approaches to immunization. Clin Microbiol Rev. 1994;7(3):277-89.

28. Mbow ML, De Gregorio E, Valiante NM, Rappuoli R. New adjuvants for human vaccines. Curr Opin Immunol. 2010;22(3):411-6.

29. Yang $X$, Ouyang $H$, Chen F, Ma T, Dong M, Wang F, Pang D, Peng Z, Ren L. Inhibition of 3-hydroxy-3-methylglutaryl-coenzyme a reductase increases the expression of interferon-responsive genes. Clin Exp Pharmacol Physiol. 2014:41(12):950-5

30. Yang X, Ma T, Ouyang H, Chen F, Peng Z, Li C, Ma Y, Chen X, Li B, Pang D, et al. Effect of atovastatin treatment on porcine circovirus 2 infection in BALB/c mice. Clin Exp Pharmacol Physiol. 2015;42(8):817-21.

31. Ma T, Ouyang $T$, Ouyang $H$, Chen F, Peng Z, Chen X, Pang D, Ren L. Porcine circovirus 2 proliferation can be enhanced by stably expressing porcine IL-2 gene in PK-15 cell. Virus Res. 2017;227:143-9. 